\title{
An Innovative Mucoadhesive Thermosensitive In situ Gelling Liquid Suppository of Metoclopramide Hydrocloride for Treatment of Nausea and Vomiting Associated with Diseases
}

\author{
Z. D. SALMAN, A.T. ALHAMDANY*AND N. Z. YOUSIF
}

Department of Pharmaceutics, College of Pharmacy, Mustansiriyah University, Baghdad, Iraq

Salman et al.: Mucoadhesive Thermosensitive In situ Gelling Liquid Suppository of Metoclopramide HCl

The main purpose of presently study was to formulate and evaluate a controlled release thermogelling mucoadhesive system of Metoclopramide Hydrocloride given for emetic patients as an alternative for conventional oral dosage forms. Twelve formulations were prepared by the addition of mucoadhesive polymers (Hydroxypropyl methylcellulose K15M and Hydroxypropyl methylcellulose K100M, carbopol 934p, and sodium alginate) to the formulations of the thermosensitive gelling solutions containing poloxamer 407 and poloxamer P188. Each of the eleven formulations containing metoclopramide Hydrocloride as an active drug was evaluated for $\mathrm{pH}$, clarity, drug content, gelation temperature, gel strength, mucoadhesive force and viscosity. While the succeeded in situ gelling liquid suppository, formulations were evaluated for spreadability, syringeability, the in vitro release profile of the drug and kinetic studies. Also, the optimum formulation was evaluated and identified for drug-excipients compatibility study using Fourier transform infrared spectroscopy. From the characterization of Metoclopramide Hydrocloride in situ gelling liquid suppositories, it was revealed that the optimized formulation (F4) displayed the best syringeability time $(7.5 \pm 0.77 \mathrm{~s})$ that is confirmed by viscosity measurement $\left(335 \pm 0.15 \mathrm{cp}\right.$ at $25^{\circ}$ and $27470 \pm 0.09 \mathrm{cp}$ at $\left.37^{\circ}\right)$ with a suitable $\mathrm{pH}$ determination $(\mathbf{7 . 0 1} \pm 0.90)$. While gelation temperature at $\left(37 \pm 0.04^{\circ}\right)$ was established with a spreadability measurement $(17.5 \pm 0.02 \mathrm{~g} \mathrm{~cm} / \mathrm{s})$. Moreover, adhesiveness at the administration site was assured by both mucoadhesive and gel strength studies that were realized to be $\left(20.90 \pm 0.83 \mathrm{dyne} / \mathrm{cm}^{2} .100\right)$ and $\left(17.5 \pm 0.34 \mathrm{~N} / \mathrm{m}^{2}\right)$, respectively. Whereas the drug release method was affirmed through in vitro drug release profile that shows good control of the release, reaching $97.5 \%$ after $3 \mathrm{~h}$ with an appropriate content uniformity at $(98.19 \pm 0.0011)$. The kinetic test of the release data was founded to obey both diffusion and erosion mechanisms, as the correlation coefficient $\left(R^{2}\right)$ was best fitted with the Korsmeyer-Peppas model and release exponent (n) shown to be between 0.5-1 that was (0.5190). Put together, our results concluded that thermosensitive liquid in-situ gelling suppositories of Metoclopramide Hydrocloride were effective, potential, and more convenient alternative for a conventional oral dosage form that was given for emetic patients; thereby improving patient compliance and medication adherencet.

Key words: Metoclopramide Hydrocloride, Liquid suppository, Thermosensitive in situ gel, HPMC K15M, Poloxamer 407, Poloxamer 188

The conventional suppository is a traditional favorable rectal dosage form for children and non-cooperating patients. Besides, an ideal suppository should be applied without any pain and remain at the administered sites to avoid the first-pass effect in the liver, therefore, the bioavailability can be increased ${ }^{[1]}$. One of the major drawbacks of suppositories is the leakage from the site of action as they melt in the cavities. Moreover, these routes have a feeling of discomfort and refusal

*Address for correspondence

E-mail: arm.anas.alhamdany@uomustansiriyah.edu.iq by the patients, thus, lowering a patient's compliance. However, these problems can be resolved using in situ gelling, bio adhesive, and liquid suppositories ${ }^{[2]}$.

This is an open access article distributed under the terms of the Creative Commons Attribution-NonCommercial-ShareAlike 3.0 License, which allows others to remix, tweak, and build upon the work non-commercially, as long as the author is credited and the new creations are licensed under the identical terms

Accepted 02 July 2020

Revised 17 June 2020

Received 03 January 2020 Indian J Pharm Sci 2020;82(4):650-664 
The liquid suppository exists as a solution at room temperature, so, it can be administered easily with a suitable applicator but at body temperature, it instantly gels in the rectum and adheres to the mucous membrane. An important eligibility criterion of the system is the suitable bioadhesivity so as not to be leaked out from the anus after administration ${ }^{[3]}$.

Several attempts have been developed using a temperature-sensitive and mucoadhesive liquid suppository through functioning numerous polymers such as poloxamer 188 (P188) and poloxamer 407 (P407), Hydroxypropyl methylcellulose K15M (HPMC K15M) and Hydroxypropyl methylcellulose K100M (HPMC K100M), carbopol 932, and sodium alginate respectively. As a base of liquid suppositories, poloxamer, a nontoxic copolymer of poly (oxyethylene)poly (oxypropylene)-poly (oxyethylene) was used. These systems are liquids before minimal invasive administration into the body. The temperature change act as a stimulus to show the sol-gel transition of poloxamer ${ }^{[4]}$. Furthermore, the bioadhesive polymers like carbopol $934 p$ and sodium alginate have a proper attribute to control the gel strength and the bioadhesive force of a liquid suppository ${ }^{[5]}$. While water-soluble HPMC K15M and K100M were used as a thermoresponsive base of the liquid suppository. These cellulose derivatives are nonionic water-soluble polymers, which can be used as a gel and film-forming agent. On heating the aqueous solution of HPMC K15M and $\mathrm{K} 100 \mathrm{M}$ to a certain temperature $(\mathrm{Tt})$, reversible thermal gelation can be observed. The background of thermal gelation is the association between the high substituted parts and the coverage of hydrophobic molecule parts in the network of the polymer chain ${ }^{[6]}$.

Metoclopramide Hydrochloride $(\mathrm{HCl})$ is a potent and popular antiemetic, effective in the treatment of nausea and vomiting induced by cancer therapy, pregnancy, migraine, and radiation sickness. It is rapidly absorbed and eliminated after oral administration. Yet, the oral bioavailability ofmetoclopramide $\mathrm{HCl}$ is highly variable, showing values between $32-98 \%$ due to extensive pre-systemic metabolism ${ }^{[7]}$. The administration of metoclopramide $\mathrm{HCl}$ is usually in a dose of 10 to 20 $\mathrm{mg}$ four times daily. Oral forms of this drug often get vomited out before systemic absorption. In long term therapy, fluctuation in the plasma concentration, with high concentration peaks are common for this type of drug that has rapid absorption and elimination when administered in conventional immediate release dosage form ${ }^{[8]}$. The oral administration results in low patient compliance. Therefore, controlled release dosage forms have the advantages of decreasing side effects, reducing dosing frequency, reducing fluctuations in circulating drug levels, and achieving a prolonged therapeutic effect by continuously releasing medication over an extended period after ${ }^{[9,10]}$. Moreover, rectal delivery seems to be an attractive alternative.

This study aims to formulate a controlled release thermogelling mucoadhesive system of metoclopramide $\mathrm{HCl}$ as an alternative for conventional oral dosage forms given for emetic patients that results in improving patient's compliance and medication adherence, also, those developed liquid suppositories help to avoid the liver's first-pass metabolism suggesting an improvement in the bioavailability of the absorbed drug.

\section{MATERIALS AND METHODS}

\section{Materials:}

Metoclopramide $\mathrm{HCl}$ was purchased from (Provizer Pharma, India), sodium alginate was obtained from (Avonchem, UK), poloxamer $(188,407)$ was supplied from (Baoji Guokang Bio-Technology, China), carbopol (934P) came from (Provizer Pharma, India), and HPMC (K15M, K100M) was purchased from (Gainland chemical company, UK). All other materials used were of pharmaceutical grade.

\section{Preparation of poloxamer-HPMC based liquid suppository:}

In this preparation, a procedure was adopted "cold method" to formulate poloxamer-HPMC based liquid suppository as shown in (Table 1). The required amounts of poloxamer (407 and 188) for each formulation were carefully weighed in a $100 \mathrm{ml}$ beaker and dispersed in an appropriate volume of distilled water. Subsequently, the beaker was placed inside an ice bath $\left(4^{\circ}\right)$ on a magnetic stirrer under continuous agitation for 30 min until a homogenized mixture was gained. The dispersion was then stored in a refrigerator overnight to get a clear solution. The required amount of HPMC (K15M and $\mathrm{K} 100 \mathrm{M}$ ) was continuously mixed with 20$30 \%$ of the desired volume of distilled water $\left(70^{\circ}\right)$ on a heated magnetic stirrer. The remaining volume of cold water was then added to the opaque mixture and stirred until it cleared up ${ }^{[11,12]}$. Afterward, both poloxamer and HPMC solutions were mixed continuously inside an ice bath at $4^{\circ}$ on a magnetic stirrer. To this mixture, metoclopramide $\mathrm{HCl}$ and distilled water were added up to $80 \mathrm{ml}$ with constant mixing then, stored in a refrigerator until use. 
Preparation of poloxamer-carbopol based liquid suppository:

Mucoadhesive polymer, carbopol 934P, was dissolved in distilled water by agitation at room temperature. After that, a cooled poloxamer (188 and 407) solution $\left(4^{\circ}\right)$ was added slowly, with agitation as shown in (Table 1). The mixture was then kept overnight at $4^{\circ}$ until a viscous and clear solution was obtained. To this successive solution, metoclopramide $\mathrm{HCl}$ and distilled water were added up to $80 \mathrm{ml}$ with constant mixing using a magnetic stirrer and inside an ice bath $\left(4^{\circ}\right)$, thereafter, stored in a refrigerator until use ${ }^{[13]}$.

\section{Preparation of poloxamer-alginate based liquid suppository:}

In the case of sodium alginate, it was dissolved primarily in the deionized water at $90^{\circ}$ for $10 \mathrm{~min}$ and cooled to room temperature. Later, a cooled poloxamer (188 and 407) solution $\left(4^{\circ}\right)$ was added slowly, with continuous agitation on a magnetic stirrer and inside an ice bath until a clear solution was acquired. Metoclopramide $\mathrm{HCl}$ and distilled water up to $80 \mathrm{ml}$ were then added to the prepared formulation, subsequently, the solution was stored in a refrigerator until use ${ }^{[14]}$. The composition of the formulation was shown in (Table 1).

\section{Characterization of metoclopramide $\mathrm{HCl}$ in situ gelling liquid suppository:}

\section{Determination of $\mathrm{pH}$ and general appearance:}

The $\mathrm{pH}$ of the prepared in situ gelling liquid suppository formulations was determined using a calibrated $\mathrm{pH}$ meter (WTW-INO LAB- Switzerland). Determinations were carried out three times then the average was taken as the $\mathrm{pH}$ of the prepared formulations. The general appearance of the prepared in situ gelling liquid suppository formulations was determined by visual inspection for color, homogeneity, and clarity under the black and white background ${ }^{[15]}$.

\section{Drug Content:}

Five $\mathrm{ml}$ of the solution was pipetted and dissolved in about $100 \mathrm{ml}$ phosphate buffer (pH 7.4) in a $250 \mathrm{ml}$ volumetric flask. One milliliter was taken and diluted to $10 \mathrm{ml}$. After shaking for $2 \mathrm{~min}$, the solution was filtered through $0.45 \mu \mathrm{m}$ pore size Millipore filter, and the absorbance of this solution was recorded at $273 \mathrm{~nm}$ against phosphate buffer (pH 7.4) as a blank using ultraviolet (UV)/visible spectrophotometer (Shimadzu 1800, Japan). Drug content studies were carried out in triplicate. The concentration of the drug present in the in situ gelling liquid suppository formulation was calculated from the equation obtained from the calibration curve ${ }^{[16]}$.

\section{Measurement of gelation temperature:}

Gelation temperature measurement was performed using a procedure reported by Lena Murad Thomas et $a l^{[17]}$. A $25 \mathrm{ml}$ transparent beaker containing a magnetic bar and $10 \mathrm{ml}$ of the in situ gelling liquid suppository formulation was placed on a magnetic stirrer (DragonLab MS-H-PRO, USA). A digital thermometer was immersed in the in situ gelling liquid suppository formulation. The formulation was heated at a constant rate $(1 \% \mathrm{~min})$ with constant stirring (200 rpm). The gelation temperature was determined as the temperature registered on the thermometer when the magnetic bar stopped moving due to gelation ${ }^{[18]}$. Each sample was measured triplicate.

TABLE 1: COMPOSITION OF METOCLOPRAMIDE HCI LIQUID BASED SUPPOSITORY

\begin{tabular}{|c|c|c|c|c|c|c|c|}
\hline Formulations & $\begin{array}{l}\text { Metoclopramide } \\
\mathrm{HCl}(\mathrm{mg}) / 5 \mathrm{ml}\end{array}$ & P407 (g) & P188 (g) & $\begin{array}{c}\text { HPMC K15M } \\
(\mathrm{g})\end{array}$ & $\begin{array}{c}\text { HPMC K100M } \\
(\mathrm{g})\end{array}$ & $\begin{array}{c}\text { Carbopol 934p } \\
\text { (g) }\end{array}$ & $\begin{array}{l}\text { Sodium } \\
\text { alginate }(\mathrm{g})\end{array}$ \\
\hline F1 & 10.5 & 7.5 & 2.5 & 0.750 & - & - & - \\
\hline F2 & 10.5 & 10 & 2.5 & 0.750 & - & - & - \\
\hline F3 & 10.5 & 12.5 & 2.5 & 0.750 & - & - & - \\
\hline F4 & 10.5 & 15 & 2.5 & 0.750 & - & - & - \\
\hline F5 & 10.5 & 15 & 5 & 0.750 & - & - & - \\
\hline F6 & 10.5 & 15 & 7.5 & 0.750 & - & - & - \\
\hline F7 & 10.5 & 15 & 2.5 & 1.5 & - & - & - \\
\hline F8 & 10.5 & 15 & 2.5 & 0.375 & - & - & - \\
\hline F9 & 10.5 & 15 & 2.5 & - & 0.750 & - & - \\
\hline F10 & 10.5 & 15 & 2.5 & - & - & 0.750 & - \\
\hline F11 & 10.5 & 15 & 2.5 & - & - & - & 0.750 \\
\hline F12 & - & 15 & 2.5 & 0.750 & - & - & - \\
\hline
\end{tabular}

Metoclopramide $\mathrm{HCl}(\mathrm{mg}) / 5 \mathrm{ml}$ : represents $10.5 \mathrm{mg}$ in each dose thus in $80 \mathrm{ml}$ equal to $168 \mathrm{mg}$, P407: poloxamer 407, P188: poloxamer 188, HPMC K15M, K100M: hydroxypropyl methylcellulose (K15M, K100M) 


\section{Measurement of gel strength:}

One of the required evaluation sof the in situ gelling liquid suppositories was the measurement of gel strength. The in situ gelling liquid suppository formulation $(50 \mathrm{ml})$ was put in a $100 \mathrm{ml}$ graduated cylinder and placed in a water bath for $30 \mathrm{~min}$ at $37 \pm 0.5^{\circ}$ to make the solution gel. The gel strength was measured by using the procedure reported by H.-R. Lin et al ${ }^{[19]}$. An apparatus having an appropriate perforated size disc (30 g) was placed on top of the in-situ gelling liquid suppositories in the cylinder. The time required for the disc to move $5 \mathrm{~cm}$ down the cylinder and through the gelled base was determined. Meanwhile, various weights were placed at the free end of the apparatus where a lightweight pan $(5 \mathrm{~g})$ is attached in case that it took more than $5 \mathrm{~min}$ to drop the apparatus into the gel. Therefore, the gel strength was described by the least weights that pushed the apparatus $5 \mathrm{~cm}$ down through the gel.

\section{Measurement of mucoadhesive force:}

Eleven in situ gelling liquid suppositories were evaluated for the mucoadhesive force using a modified balance according to the preceding declared method ${ }^{[20]}$. A section of sheep rectal tissues was cut and promptly held with mucosal side out onto two glass vials using a rubber band. The exposed diameter of each mucosal membrane was $15 \mathrm{~mm}$. The vials containing the rectal tissues on their ends were preserved at $37 \pm 0.5^{\circ}$ for $10 \mathrm{~min}$ before measuring the mucoadhesive force. One vial with a section of tissue was joined to the balance instead of one of the pans by a height-adjustable hook, and the other vial was set with $(0.15 \mathrm{~g})$ gel spread on it and its height altered so that the gel could contact with the mucosal tissues of both vials and was permitted to adhere for $3 \mathrm{~min}$ (preload time).

On the other side of the balance, a plastic cup to collect water was placed. Water was added drop by drop to the plastic cup until the weight of water in the cup detached the two surfaces from each other. The mucoadhesive force of the liquid suppository per unit area (F), expressed as the detachment stress $\left(\right.$ dyne $\left./ \mathrm{cm}^{2}\right)$, was determined from the minimal weight of water that detached the two vials and was calculated using the following equation: $F=0.98 \mathrm{~m} / \pi r^{2}$

where $\mathrm{m}$ represents the weight $(\mathrm{g})$ of water required for detachment, and $\mathrm{r}$ represents the radius $(\mathrm{mm})$ of the mucosal membrane. Measurements were repeated triplicate for each of the in situ gelling liquid suppository formulations. The rectal mucosal tissue was replaced for each measurement.
Viscosity measurements of the liquid suppository:

The viscosity of in situ gelling liquid suppositories was affirmed using a Brookfield digital viscometer (LVDV-E, USA). A $15 \mathrm{ml}$ sample of each formulation was placed in a glass container. Primarily, viscosity measurement was recorded at $25 \pm 1^{\circ}$, and then the temperature was elevated to reach at $37 \pm 0.5^{\circ}$ by a water jacket through which water was circulated at $37 \pm 0.5^{\circ}$ from a thermostat bath. For the determination of viscosity values, a spindle with the number 63 and rotating speed of $50 \mathrm{rpm}$ was used for measurements at $25 \pm 1^{\circ}$, while a spindle with the number 64 and rotating speed of $50 \mathrm{rpm}$ was used for the measurements at $37 \pm 0.5^{\circ[21]}$. All measurements were performed in triplicate and the mean value was calculated.

\section{Measurement of spreadability for liquid suppositories:}

For measuring spreadability, a specially fabricated laboratory apparatus was suitably modified and utilized for the study. The glass slides were maintained at a constant temperature of $37^{\circ}$ by a hot plate magnetic stirrer. $2 \mathrm{ml}$ of in situ gelling liquid suppository was applied within a circle of $1 \mathrm{~cm}$ diameter pre-marked on a ground rectangular glass plate over which a second rectangular glass plate was placed. The two plates were compressed to uniform thickness under tension by placing $(500 \mathrm{~g})$ weight on the top plate for $5 \mathrm{~min}$ to expel air and to provide a uniform film of the in situ gelling liquid suppositories between the plates. The top plate (provided with a hook) was then exposed to a pull of $50 \mathrm{~g}$ with the aid of a string tied with a hook. Spreadability was measured depending on the time in sec in which the top plate slips off from in situ gelling liquid suppositories before getting gelled and as shown in (fig. 1). The increment in diameter was noted owing to the spreading of the in situ gelling liquid suppositories. A shorter interval shows preferable spreadability and an average of three obtained readings were recorded ${ }^{[22]}$. The calculation of spreadability (S) is as the following: $\mathrm{S}=\frac{\mathrm{ML}}{\mathrm{T}}$ (expressed in $\mathrm{g} \mathrm{cm} \mathrm{sec-1}$ (gram centimeter/sec) Where, $\mathrm{M}=$ Weight tide to upper slide $(\mathrm{g}), \mathrm{L}=$ =ength moved on the glass slide $(\mathrm{cm}), \mathrm{T}=$ Time taken.

\section{Measurement of syringeability for liquid suppositories}

The syringeability of the in situ gelling liquid suppositories was evaluated with a fabricated laboratory device. This device was composed of vertical support (clamp) for a $5 \mathrm{ml}$ plastic Luer lock syringe filled with 


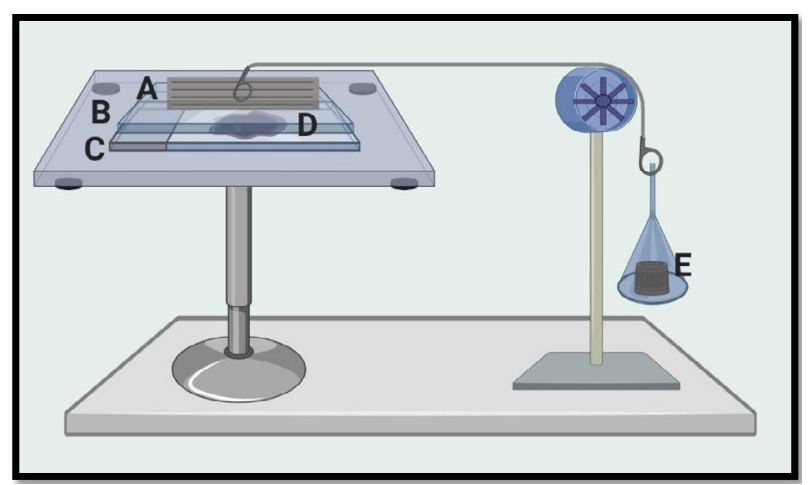

Fig. 1: Illustrated diagram of fabricated laboratory apparatus used for measuring spreadability

A: weight $500 \mathrm{~g}$, B: top rectangular glass plate, C: ground rectangular glass plate, $\mathrm{D}: 2 \mathrm{ml}$ in situ gelling liquid suppositories, E: weight $50 \mathrm{~g}$.

in situ gelling liquid. A second clamp for grasping a hollow holder and a weight (1000 g) moving downwards until it came in contact with the piston to support a constant force of $0.5 \mathrm{~N}$ on the piston syringe as shown in (fig. 2). A 23G. $1^{1 / 4}$ inches needle was fixed on the syringe which was positioned in the support. The time necessary for the in situ gelling liquid to be expelled from the syringe was measured ${ }^{[23]}$. The tests were conducted at room temperature $25^{\circ}$ and each experiment was carried out three times.

\section{In vitro release from liquid suppository:}

The release experiment studies of metoclopramide $\mathrm{HCl}$ from in situ gelling liquid suppository formulations were monitored using the in vitro dialyzing method in which $5 \mathrm{ml}$ of the prepared liquid suppository formulation was syringed into a glass container closed at one end and the open end covered by a $1.8 \mathrm{~cm}$ cap in diameter of a hydrophilic membrane of regenerated cellulose millipore $0.45 \mu$ (soaked for $1 \mathrm{~h}$. before the test in the phosphate buffer), and heated for $10 \mathrm{~min}$ to gelate completely ${ }^{[24]}$. This glass apparatus was fixed on the paddle with threads to prevent leakage, on type II dissolution apparatus (PHARMA TEST DFC-820SP, Germany) and the release medium $500 \mathrm{ml}$ phosphate buffer ( $\mathrm{pH}$ 7.4) was used as a dissolution medium pre-equilibrated at $37^{\circ}$, throughout $4 \mathrm{~h}$ and stirred at $100 \mathrm{rpm} .5 \mathrm{ml}$ samples were withdrawn at regular time intervals and replaced with the same volume of fresh dissolution medium. The samples were analyzed spectrophotometrically at $\lambda_{\max } 273 \mathrm{~nm}$ using a UV/ visible spectrophotometer (Shimadzu 1800, Japan) ${ }^{[25]}$. Each experiment was performed in triplicate.

\section{Kinetic evaluations:}

The results of dissolution rate data obtained were evaluated kinetically by zero-order, first-order, and
Higuchi models to establish the release kinetics and mechanism of drug release. Based on the correlation coefficient $\left(\mathrm{R}^{2}\right)$ value in various models, the model that gives the highest $\left(\mathrm{R}^{2}\right)$ value is deemed as the best fit of the release model. Moreover, when the mechanism of release of metoclopramide $\mathrm{HCl}$ from liquid suppository is not well known, the first $60 \%$ drug release data were fitted in Korsmeyer-Peppas equation: $\mathrm{M}_{\mathrm{t}} \mathrm{M}_{0}=\mathrm{Kt}^{\mathrm{n}}$. Where M0 is the initial amount of drug released at zero time, $\mathrm{Mt}$ is the amount of drug released at time $\mathrm{t}, \mathrm{Mt} /$ $\mathrm{M} 0$ is the fraction of drug released at time $\mathrm{t}, \mathrm{K}$ is a release characteristic constant of the suppository and $n$ is a release exponent related to the mechanism of the drug release. As the $\mathrm{k}$ value becomes higher, the drug is released faster. The $\mathrm{n}=1$ corresponds to zero-order release if possible, if " $n$ " $>1$, a super Case II transport is operative, if $0.5<\mathrm{n}<1$ it suggest anomalous transport (non-Fickian) release model due to both drug diffusion and polymer chain relaxation, and for $n \leq 0.5$ indicate Fickian diffusion (Higuchi's model) ${ }^{[26,27]}$.

\section{Statistical Analysis:}

Statistical analysis was accomplished using Microsoft Excel 2016 software. The results obtained for the drug release were reported as means \pm standard deviations $[\mathrm{SD}](\mathrm{n}=3)$. Differences in parameters from formulations were statistically analyzed by one-way analysis of variance (ANOVA) at a $95 \%$ confidence interval. Statistically significant differences were defined as $\mathrm{p}<0.05^{[28]}$.

\section{Drug-excipients interaction study and identification:}

\section{Fourier transform infrared spectroscopy (FT-IR):}

The FT-IR spectra of pure drug, polymers (poloxamer 407,188 and HPMC K15M), and the drug with the

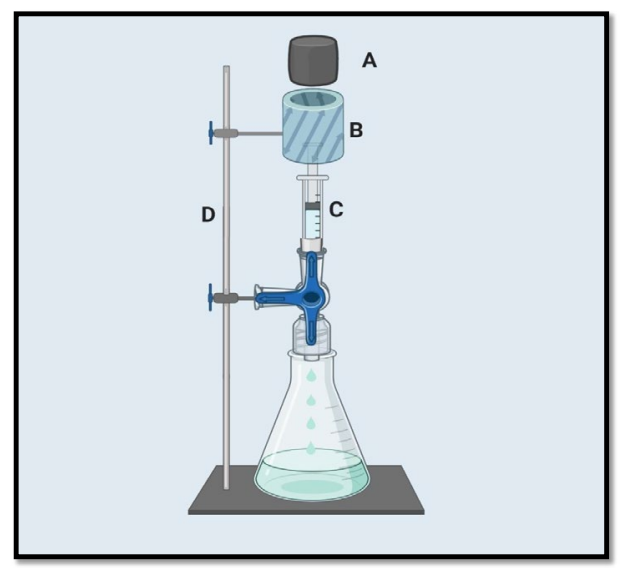

Fig. 2: Illustrated diagram of fabricated laboratory apparatus used for measuring syringeability A: weight $1000 \mathrm{~g}, \mathrm{~B}$ : hollow holder to grasp the weight, $\mathrm{C}$ : syringe filled with $5 \mathrm{ml}$ in situ gelling liquid suppositories, D: double clamp with rack. 
polymer (after the in-situ gelling liquid suppository formed as a gel at $37 \pm 0.5^{\circ}$, the formulation was permitted to dry in the air) were recorded on a spectrophotometer (Shimadzu 8400S, Japan) using the potassium bromide $(\mathrm{KBr})$ pellet technique and spectra was recorded in the transmittance mode with 25 scans acquired at $2 \mathrm{~cm}^{-1}$ resolution, between 4000 and $450 \mathrm{~cm}^{-1}$. The spectra FT-IR records the existence and identification of the functional groups in the formulations. FT-IR spectra were obtained to investigate any physicochemical incompatibility interaction between the pure drug and different excipients in the prepared formulations ${ }^{[29]}$.

\section{RESULTS AND DISCUSSION}

Characterization of the in-situ gelling liquid suppository system is a major issue to be considered in the formulation stage, especially those intended for rectal administration.

The clarity of the formulated in situ gelling liquid suppositories was found to be transparent at room temperature with a smooth and homogenous appearance. Generally, the properties of rheological fluids can be influenced by the $\mathrm{pH}$ of the dispersion medium, because it can change the gelation process and the gel structure. In our study, the $\mathrm{pH}$ of prepared liquid suppositories is shown in (Table 2). They were found to be in the range of 7.01-7.44; this range is considered to be close to the $\mathrm{pH}$ of the rectum and is an indication of the suitability for rectal application with minimal risk of tissue irritation ${ }^{[17]}$.

The determined drug content values were ranged from 98.29 to 101.00 as shown in (Table 2) and this indicates homogeneity of the drug in the in situ gelling liquid suppository formulations. The difference in drug content from different formulations may be due to their different $\mathrm{pH}$ and electrolyte in their formulations ${ }^{[27,30]}$.

Gelation temperature measurement was performed in this study due to a remarkable property that should exist in the in situ gelling liquid suppositories when given to the patients; which is the transition of the liquid phase to a gel when temperature varied. It has been notified that an acceptable in situ gelling liquid suppository should possess a gelation temperature between 30 and $37^{\circ}$, to be in a liquid form at room temperature, and capable to form a gel phase immediately in the rectum ${ }^{[13]}$.

Poloxamer solutions were recognized to show thermoreversible, temperature-dependent gelation, based on the polymer grade, concentration, and other involved formulation components. Preceding findings showed that neither P407 nor P188 alone could provide gelation at the physiological temperature. Using a combination of two poloxamer grades, gelation temperature could be modulated to the desired range ${ }^{[4]}$. The temperature-dependent gelation of poloxamer solutions could be explained to be due to the desolvation of hydrophilic chains of the polymer as a result of the breakage of the hydrogen bonds that have been established between the solvent and these chains. This phenomenon favors hydrophobic interaction among the hydrophobic chains of the polymer and the polymer self-assemble spontaneously, forming micelles ${ }^{[31]}$.

The increment in P407 concentration in formulations (F1-F4) resulted in lower gelation temperatures; this could be elucidated by the increase in the quantity of micelles formation and increased the possibility of micelle entanglement and packing with each other ${ }^{[32]}$.

Formulations (F4-F6) show the effect of P188 concentration on gelation temperature, the increment of P188 concentration was accompanied by an increase in the gelation temperature of formulations. A conceivable reason for this is due to the small amount of P188 incorporated compared to the amount of P407 which only resulted in changing the poly-ethylene oxide/ polypropylene oxide (PEO/PPO) ratio and an increment in gelation temperature without affecting the micellization process and participation of P188 molecules in the construction of the gel ${ }^{[33]}$.

It was observed that gelation temperature depends on the type and concentration of mucoadhesive polymer used in the formulation. All studied mucoadhesive polymers lowered the gelation temperature; the results showed that increasing the concentration of HPMC $\mathrm{K} 15 \mathrm{M}(\mathrm{F} 8, \mathrm{~F} 4$, and F7) produced a significant $(\mathrm{p}<0.05)$ decrease gelation temperature of the corresponding liquid suppositories as shown in (Table 2) ${ }^{[20]}$. Moreover, formulations (F9, F10, and F11) prepared by the addition of HPMC K100M, carbopol 934p, and sodium alginate respectively, as mucoadhesive polymers to the in situ gelling liquid suppository preparations instead of adding HPMC K15M in the formulation (F4). It was noted that the gelation temperature became lower (36, 34 , and $33^{\circ}$ ), respectively, as shown in (Table 2). This was attributed to their ability to bind to the polyoxyethylene chains present in the poloxamer molecules. This will promote dehydration, causing an increase in an entanglement of adjacent molecules and extensively increasing intermolecular hydrogen bonding, which will lead to gelation at a lower temperature ${ }^{[34,35]}$. 
TABLE 2: PHYSICOCHEMICAL PROPERTIES OF METOCLOPRAMIDE HCI IN SITU GELLING LIQUID SUPPOSITORIES

\begin{tabular}{|c|c|c|c|c|c|}
\hline Formulations & $\mathrm{pH}$ & $\begin{array}{l}\text { Drug Content } \\
\text { (\%) }\end{array}$ & $\begin{array}{c}\text { Gelation } \\
\text { temperature }\left({ }^{\circ}\right)\end{array}$ & $\begin{array}{l}\text { Gel Strength } \\
\left(\mathrm{N} / \mathrm{m}^{2}\right)\end{array}$ & 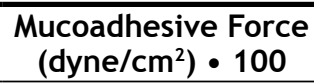 \\
\hline F1 & $7.35 \pm 0.11$ & $98.57 \pm 0.0031$ & $52 \pm 0.14$ & $11.1 \pm 0.02$ & $15.89 \pm 2.04$ \\
\hline F2 & $7.23 \pm 0.09$ & $102.76 \pm 0.002$ & $50 \pm 0.07$ & $14.2 \pm 0.12$ & $16.73 \pm 0.73$ \\
\hline F3 & $7.12 \pm 0.14$ & $93.23 \pm 0.0013$ & $45 \pm 0.11$ & $16.4 \pm 0.22$ & $18.82 \pm 1.76$ \\
\hline F4 & $7.01 \pm 0.90$ & $98.19 \pm 0.0011$ & $37 \pm 0.04$ & $17.5 \pm 0.34$ & $20.90 \pm 0.83$ \\
\hline F5 & $7.06 \pm 0.10$ & $96.98 \pm 0.0034$ & $58 \pm 0.09$ & $19.6 \pm 0.06$ & $23.01 \pm 0.55$ \\
\hline F6 & $7.1 \pm 0.80$ & $100.12 \pm 0.0032$ & $62 \pm 0.12$ & $22.4 \pm 0.17$ & $26.12 \pm 1.62$ \\
\hline F7 & $7.08 \pm 0.24$ & $102.89 \pm 0.0021$ & $32 \pm 0.05$ & $13.2 \pm 0.45$ & $22.84 \pm 1.06$ \\
\hline F8 & $7.13 \pm 0.03$ & $98.28 \pm 0.0014$ & $38 \pm 0.16$ & $9.8 \pm 0.33$ & $14.33 \pm 0.98$ \\
\hline F9 & $7.25 \pm 0.33$ & $99.96 \pm 0.0024$ & $36 \pm 0.21$ & $15.3 \pm 0.42$ & $24.72 \pm 1.50$ \\
\hline F10 & $6.82 \pm 0.34$ & $100.78 \pm 0.0027$ & $34 \pm 0.03$ & $13.6 \pm 0.33$ & $32.21 \pm 0.97$ \\
\hline F11 & $7.44 \pm 0.21$ & $101.86 \pm 0.0038$ & $33 \pm 0.31$ & $10.9 \pm 0.16$ & $56.44 \pm 0.46$ \\
\hline F12 & $7.11 \pm 0.23$ & - & $35 \pm 0.17$ & $15.3 \pm 0.23$ & $10.23 \pm 0.63$ \\
\hline
\end{tabular}

Data were given in mean $\pm S D, n=3$

Since metoclopramide $\mathrm{HCl}$ is the active material of the prepared in situ gelling liquid suppository (F4), thus its effect on the physicochemical characteristics of these suppositories should be studied. During the experiments, the amount of metoclopramide $\mathrm{HCl}$ incorporated in these rectal dosage forms was found to increase the gelation temperature on the contrary to the formulation prepared without using active ingredient (F12) as shown in (Table 2). This is maybe associated with the fact that these water-soluble substances cause modification of the process of micellar association of poloxamer solutions leading to an increase in gelation temperature ${ }^{[26]}$.

Gel strength measurement of the in situ gelling liquid suppository is considered as an important signal for the viscosity of the solution at physiological temperature. Therefore, it is deemed as a vital parameter in the development of in situ gelling rectal suppositories, thus, to find the suitable condition of moderate gel strength which allows the easy insertion of these in situ liquid suppositories and prevents their leakage from the anus after insertion when the gel strength is low.

Gel strength was affected by the concentration of poloxamer used. Increasing the concentration of P407 $(\mathrm{F} 1-\mathrm{F} 4)$ resulted in a significant $(\mathrm{p}<0.05)$ increase in the gel strength. This could be a result of the enlargement of micelles and tight packing of adjacent micelles leading to gel formation at lower temperatures. The gel is more entangled at a higher concentration of $\mathrm{P} 407^{[36]}$. In the case of P188, increasing the concentration of liquid suppository F4-F6 was accompanied by shifts in both micellization and gelation (micelle rearrangement).
Nevertheless, the effect of P188 on gelation (sol-gel transition) was found to be more noticeable than on micellization. This is probably because their effects on poly-ethylene oxide (PEO) chains are more important than their effects on poly-propylene oxide (PPO) cores. It is generally accepted that the monitor of micellization is the dehydration of the PPO block, and that once the micelles formed; the rearrangement of micelles depends on the interaction between the hydroxylic groups. It is reasonable to suppose that the presence of P188 may disturb the formation of hydrogen bonds between the micelles of $\mathrm{P} 407$, in which case the gelation becomes more difficult, and thus gelation temperature increases $^{[37]}$.

Also, gel strength measurement was likewise conducted for in situ gelling liquid suppository formulations after incorporation of a mucoadhesive polymer (HPMC K15M) for comparative evaluation (F8, F4, and F7) as shown in (Table 2). It may reveal that the addition of HPMC K15M increased the gel strength of formulations significantly $(p<0.05)$ in a concentrationdependent technique. The mechanism of increment might be associated with hydrogen bonding between poloxamer and the mucoadhesive polymer in the rectal ge $^{[38]}$. Moreover, a decreasing order in the gel strength values was observed (Table 2) after the addition of mucoadhesive polymers [HPMC K100M (F9), carbopol $934 \mathrm{p}$ (F10), and sodium alginate (F11)] as an alternative of adding HPMC K15M (F4). This might be assigned to that, the polymer with hydrophilic groups as the carboxyl and hydroxyl groups can be bind strongly to the oligosaccharide chains by firming hydrogen bonds, electrostatic attraction, or hydrophobic interaction ${ }^{[39]}$. 
Furthermore, incorporation of metoclopramide $\mathrm{HCl}$ into in situ gelling liquid suppositories (F4) could increase the gel strength. Otherwise, formulation (F12) displays a less gel strength when the drug was not incorporated into it as shown in (Table 2). A possible mechanism by which metoclopramide $\mathrm{HCl}$ affected the gel strength was speculated to be due to the hydrophilic nature (water-soluble) of the drug that could bind strongly with the cross-linked reticular structure of the poloxamer gel ${ }^{[40]}$.

Mucoadhesive measurement is an important parameter to be measured for rectal formulations including in situ gelling liquid suppositories. This physicochemical property indicates the bioadhesive force needed to prevent gelled suppositories from reaching the upper part of the rectum where the first-pass effect is probable. Also, liquid suppositories must have suitable bioadhesive strength meanwhile if the bioadhesive force is too excessive, the gel can damage the rectal mucous membrane. Whereas if bioadhesive force is inadequate then rapid leakage will occur and the retention time in the rectum will decrease ${ }^{[41]}$.

In the current study, as shown in (Table 2), the mucoadhesive force was affected by the concentration of poloxamer used. Primarily, the mucoadhesive force was increased with the increment in P407 concentration. Chain entanglement and physical interlinking interaction of the P407 with the mucous membrane could be the main reason for this highly effective mucoadhesion ${ }^{[2,43]}$. Then, the effect of adding P188 to the in situ gelling liquid suppositories, which is homologous of P407, was found to enhance mucoadhesive force. This may be due to the binding of the hydrophilic oxide group of poloxamer to the oligosaccharide chains. Thus, the higher the concentration of P188, the greater the mucoadhesive force of poloxamer gels ${ }^{[44]}$.

Moreover, increment in the concentration of different mucoadhesive polymers (F9-F11) results in an increase of the mucoadhesive force as compared to (F4) as shown in (Table 2). This may be due to increasing the bond-forming groups and more adhesive sites at the polymer chains for interpenetration with mucin, resulting accordingly in an increase in mucoadhesive strength. The mucoadhesive polymers can be arranged according to their mucoadhesive force enhancing effect at $0.75 \mathrm{gm}$ of liquid suppositories as sodium alginate $>$ carbopol $934 \mathrm{p}>$ HPMC K100M. The mechanism of the mucoadhesion may be related to the abundance of secondary bond-forming groups (e.g. hydroxyl, carboxyl, and ether groups) in these polymers that increase hydrogen bonding between the gel formulation and mucosal membrane ${ }^{[45-47]}$.

The incorporation of metoclopramide $\mathrm{HCl}$ into poloxamer gel (F4) increased the mucoadhesive force as compared to (F12) where the drug was not added and as shown in (Table 2). This can be elucidated by the increase in water uptake into the gel matrix due to the amalgamation of metoclopramide $\mathrm{HCl}$ leading to facilitate the interaction between the polymer and mucus and thus producing higher mucoadhesive strength ${ }^{[48]}$.

The viscosity of in situ gelling liquid suppositories affected the drug release rate and the distribution in the distal portion of the large intestine. Furthermore, the relative viscosity might offer some insight into the predictable retention time and mucoadhesive strength of the gel. Additionally, the rheological properties evaluation of the formulation as a dosage form would be vital for expecting their behavior in $v i v o^{[27]}$. The viscosity of the in situ gelling liquid suppositories in the tested experimental conditions as shown in (Table 3).

The effect of temperature on viscosity of metoclopramide $\mathrm{HCl}$ in situ gelling liquid suppositories at $25^{\circ}$ was established on all formulation solutions (F1-F12) and shown in (Table 3). It was confirmed that these formulations were in liquid form at room temperature with low viscosity and exhibited a Newtonian behavior. Therefore, to ensure an easy administration and a homogeneous spreading of the formulation on the $\operatorname{mucosa}^{[49]}$.

At $37^{\circ}$, the behavior of P407 solutions changed, depending on the amount of polymer used. As the

\section{TABLE 3: VISCOELASTIC PROPERTIES OF METOCLOPRAMIDE HCI IN SITU GELLING LIQUID SUPPOSITORIES}

\begin{tabular}{lcc}
\hline RPM 5 & \multicolumn{2}{c}{ Viscosity $(C p)$} \\
\cline { 2 - 3 } Formulations & At $25^{\circ}$ & At $37^{\circ}$ \\
F1 & $197 \pm 0.34$ & $12630 \pm 0.14$ \\
F2 & $226 \pm 0.56$ & $18540 \pm 0.74$ \\
F3 & $284 \pm 0.62$ & $21230 \pm 0.41$ \\
F4 & $335 \pm 0.15$ & $27470 \pm 0.09$ \\
F5 & $397 \pm 0.24$ & $28370 \pm 0.13$ \\
F6 & $410 \pm 0.46$ & $30120 \pm 0.38$ \\
F7 & $468 \pm 0.04$ & $38880 \pm 0.14$ \\
F8 & $266 \pm 0.51$ & $23750 \pm 0.52$ \\
F9 & $440 \pm 0.22$ & $39420 \pm 0.67$ \\
F10 & $420 \pm 0.77$ & $37550 \pm 0.65$ \\
F11 & $380 \pm 0.35$ & $31360 \pm 0.56$ \\
F12 & $350 \pm 0.11$ & $27160 \pm 0.21$ \\
\hline
\end{tabular}

Data were given in mean $\pm S D, n=3$ 
amount of P407 in the prepared in situ gelling liquid suppositories increased (F1-F4), the apparent viscosity increased with an increase in gelation properties which confirmed the (pseudoplastic) behavior (Table 3). Besides, it is well recognized that poloxamers are amphiphilic polymers and display a thermo-reversible performance in aqueous solution at concentrations over the critical value, identified as critical micellar concentration (CMC). Thus, the viscosity of $\mathrm{P} 407$ solution increased as the temperature is higher than $30^{\circ}$, the aggregation of poloxamer molecules into spherical micelles, constituted by a core of dehydrated hydrophobic propylene oxide (PO) and by a shell of hydrated hydrophilic ethylene oxide (EO), results in system gelation ${ }^{[50]}$.

The evaluation for the rheological properties of the in situ gelling liquid suppositories comprising P188, a non-Newtonian flow was a typical property for these formulations at higher temperatures. With continuous agitation, all formulations (F4-F6) exhibited pseudoplastic flow at $37^{\circ}$ as it was expected due to their thermoresponsive property. Otherwise, at higher concentrations of $\mathrm{P} 188$, the elastic properties tend to increase and interchain entanglements do not have sufficient time to come apart ${ }^{[51]}$.

From results, it was found that as the concentration of HPMC K15M increased (F7>F4 $>$ F8) the viscosity of in situ gelling liquid suppositories was increased (Table 3). This was due to the water-absorbing capacity of hydrophilic polymers (HPMC K15M), which has increased viscosity ${ }^{[52]}$.

It was noted that the viscosity of the rectal in situ gelling liquid suppositories comprising mucoadhesive polymers (F9-F11) increased upon increasing temperature up to $37^{\circ}$ as shown in (Table 3), and some of these liquid suppositories exhibited high viscosity to the extent that affects negatively on the spindle of the Brookfield's apparatus. The flow action of these formulations was increased orderly $(\mathrm{F} 9<\mathrm{F} 10<\mathrm{F} 11)$ and thus confirmed the pseudoplastic properties of these rectal in situ gelling liquid suppositories ${ }^{[13]}$. It was noticed that the viscosity of F9 (HPMC K100M) increased as shown in (Table 3) as the temperature increased up to $37^{\circ}$. Increasing consistency was ascribed to enhanced polymeric entanglements, thereby increasing the resistance to deformation ${ }^{[53]}$. Regarding F10 (carbopol 934p), it is suggested that increment in the number of micelles created will be due to the effect of negative coefficient solubility of block copolymer micelles. Lately, the micelles turn into closely packed that the solution turns out to be immobile and gel is created. Additionally, the conformational modifications in the orientation of the methyl groups in the side chains of poly (oxypropylene) polymer chains, establishing the core of the micelle, with the removal of the hydrating water from the micelles will participate to the gelation phenomenon ${ }^{[54]}$. While comparing these formulations, it was noticed that F11 prepared with sodium alginate had the highest shear thinning effect that indicates a thixotropic behavior. The decrease in viscosity could be attributed to the increased intermolecular distances as a result of thermal expansion with the increase of temperature ${ }^{[55]}$. It was noticed from the results as comparing $\mathrm{F} 4$ to $\mathrm{F} 12$, that the drug concentration has a non-significant effect on viscosity. This may be ascribed to the amount of drug in the formulation (F4) that could be insignificant.

Spreadability measurements were performed only to those formulations containing metoclopramide $\mathrm{HCl}$ with a promising gelation temperature (F4, F7-F11).

Formulations (F8, F4, and F7) were studied for their spreadability and it was detected to be satisfactory (Table 4). From the data attained, it can be said that an increase in HPMC concentration results in a less spreadability of the prepared in situ gelling liquid suppository formulations. A high viscosity and bioadhesive property of the HPMC K15M could be responsible for this decline in the spreadability ${ }^{[56]}$.

The spreadability of the prepared in situ gelling liquid suppositories (F9, F10, and F11) was significantly $(p<0.05)$ decreased as shown in (Table 4$)$. This possibly was as a result of a high viscosity range of these polymers (HPMC K100M, carbopol 934, and sodium alginate). Consequently, a high repulsion between hydrophilic chains and an increased cross-linking between hydrophobic chains of the polymer thus a poor spreadability may occur ${ }^{[52,57,58]}$.

TABLE 4: SPREADABILITY AND SYRINGEABILITY PROPERTIES OF THE SELECTED IN SITU GELLING LIQUID SUPPOSITORIES

\begin{tabular}{lcc}
\hline Syringeability (s) & $\begin{array}{c}\text { Spreadability } \\
(\mathbf{g ~ c m} / \mathbf{s})\end{array}$ & Formulations \\
\hline $7.5 \pm 0.77$ & $17.5 \pm 0.02$ & $\mathrm{~F} 4$ \\
$12.8 \pm 0.82$ & $8.8 \pm 0.08$ & $\mathrm{~F} 7$ \\
$6.25 \pm 0.22$ & $19.5 \pm 0.05$ & $\mathrm{~F} 8$ \\
$10.82 \pm 0.79$ & $11.33 \pm 0.13$ & $\mathrm{~F} 9$ \\
$9.12 \pm 0.62$ & $14.5 \pm 0.07$ & $\mathrm{~F} 10$ \\
$8.6 \pm 0.99$ & $15.7 \pm 0.04$ & $\mathrm{~F} 11$ \\
\hline
\end{tabular}

Data were given in mean $\pm S D, n=3$ 
A syringeability test was conducted to ensure that the prepared formulations were having a proper solution flow nature. Moreover, to determine the time taken to expel the in situ gelling liquid suppositories to the target site by application of a constant force and this termed as syringeability time. Throughout the administration of these liquid suppositories into the rectum, syringeability time plays a vital role. It is dependent on four parameters: viscosity of in situ gelling liquid suppositories, concentration of the polymer, characteristics of needle utilized in the study, and injection flow rate. The latter two parameters were kept constant while syringeability time was a characteristic of in situ gelling liquid suppositories viscosity and imputed to the polymer concentration ${ }^{[59]}$.

Besides, syringeability time is an alternative vital parameter for the practical administration of thermosensitive mucoadhesive polymers that were used in this study. As shown in (Table 4) formulations (F7, F4, and F8) containing ascending order concentration of HPMC K15M which is a long-chained, nonionic polymer. Depending on the results, it was detected that as the concentration of HPMC increased, higher viscosity and longer syringeability time will be recorded ${ }^{[60]}$.

Depending on syringeability studies of prepared in situ gelling liquid suppository formulations, the differences among these values in the formulations (F4, F9, F10, and F11) was realized to be significant $(p<0.05)$ and as shown in (Table 4). This could be referred to as higher viscosity of (F9, F10, and F11) as compared to F4 so further syringeability time would be taken to expel these formulations ${ }^{[61,62]}$.

Formulations (F1-F12) of metoclopramide $\mathrm{HCl}$ in situ gelling liquid suppository formulations were characterized via different parameters in this workstudy $(\mathrm{pH}$, general appearance, drug content, gelation temperature, gel strength, mucoadhesive force, and viscosity). Thereafter, certain formulations were chosen to perform the release studies according to the best insitu gelling properties they were possessing. These formulations were consisting of a constant amount of P407 (15 g) and P188 (2.5 g) with variable amounts of HPMC K15M (0.375 g, $0.75 \mathrm{~g}, 1.5 \mathrm{~g})$, that were represented in formulations [F8, F4 and F7]. In addition to the formulations [F9] containing HPMC K100M $(0.75 \mathrm{~g})$ and [F11] containing sodium alginate $(0.75 \mathrm{~g})$.

The accumulative percentage release of metoclopramide $\mathrm{HCl}$ was calculated. Therefore, metoclopramide $\mathrm{HCl}$ with different bases showed almost complete drug release character within approximately $4 \mathrm{~h}$. The results of F8, F4, and F7 showed in (fig. 3); elucidated that increasing the polymer concentration (HPMC K15M) led to retard in the drug release rate. This could be because the drug release from swellable hydrophilic polymer depends on the thickness of the hydrated layer. Hence, increasing polymer concentration led to increasing the thickness and swelling of the developed gel, giving a longer diffusion path length that considerably reduced the penetration of the dissolution medium and slows down drug release. Moreover, this increment in polymer concentration results in the formation of a strong matrix layer caused by intimate contact between the particles of HPMC leading to a decrease in mobility of drug particles in swollen matrices, which lead up to a decrease in the drug release ${ }^{[63]}$.

The comparison of the release profile of F4 (HPMC K15M) and F9 (HPMC K100M) in (fig. 3) showed the effect of using different grades of HPMC $(0.75 \mathrm{~g})$ on the drug release. Thus, the results revealed that increasing HPMC grade led to faster hydration and rapid formation of a dense and thick gel that slows down further water uptake that consequently decreases in drug release. Also, these higher HPMC grades had higher intrinsic water holding capacity and the gelled matrices formed from such polymers were less disposed to erosion and would reduce the effective molecular diffusion area and hence decreased drug permeation across the matrix gel $^{[64,65]}$.

Moreover, formulation 11 containing sodium alginate as shown in (fig. 3) has a slower dissolution rate. This may be due to extensive swelling of the polymer which created a high viscosity gel barrier for drug diffusion that hindered the passage of solvent and leading to a decrease in the drug release ${ }^{[66]}$.

Interestingly, high rectal drug concentration persisted for up to $4 \mathrm{~h}$ after metoclopramide $\mathrm{HCl}$ released from in situ gelling liquid suppository formulation, whereas, conventional suppositories remained at lower rectal drug concentration. This could be explained by it having a large releasing area, longer retention time, and contained more dissolved active ingredient than metoclopramide $\mathrm{HCl}$ conventional suppository ${ }^{[67]}$.

To evolve an ideal kinetic model to interpret the in vitro drug release data for the selected formulations in terms of meaningful parameters, various kinetic models including zero-order, first-order, Higuchi and Korsmeyer-Peppas models were applied to obtain the best fit for the results. 


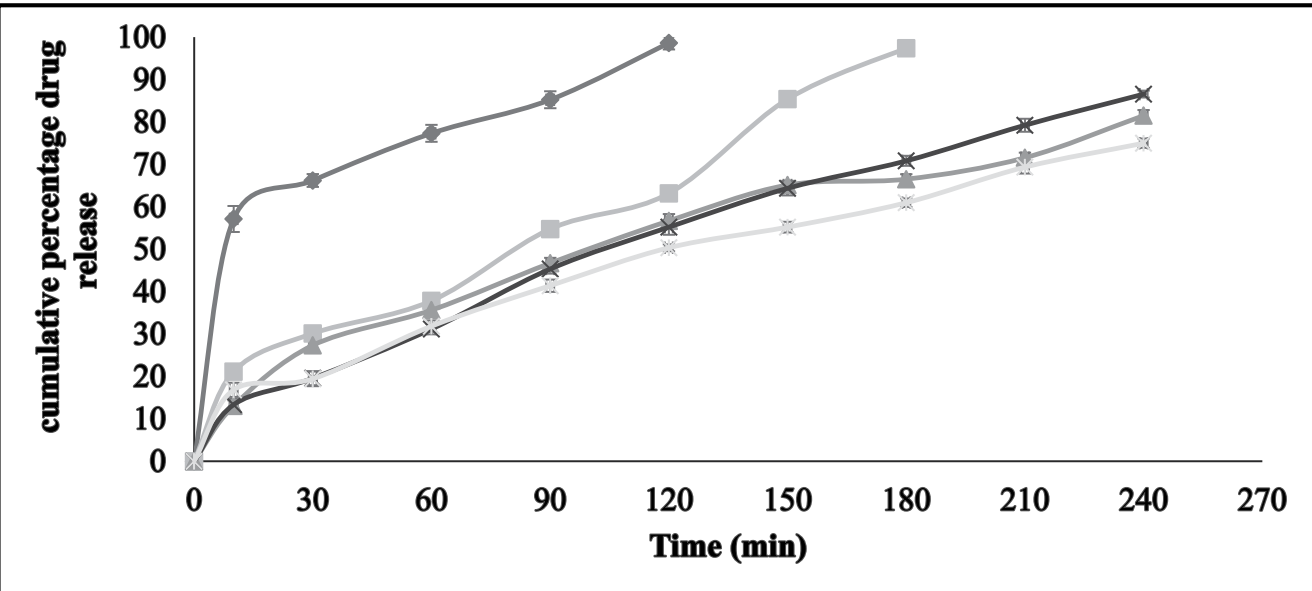

Fig. 3: Dissolution profile of metoclopramide $\mathrm{HCl}$ from in situ gelling liquid suppository

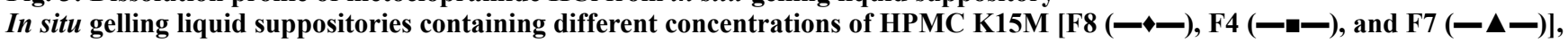
HPMC K100M [F9] (-x-), and sodium alginate [F11] (-*-), data were given in mean \pm SD, $n=3$.

TABLE 5: KINETIC DATA MODELS FOR THE SELECTED IN SITU GELLING LIQUID SUPPOSITORIES

\begin{tabular}{lccccccccc}
\hline \multirow{2}{*}{ Formulation } & \multicolumn{2}{c}{ Zero-order } & \multicolumn{2}{c}{ First-order } & \multicolumn{2}{c}{ Higuchi-order } & \multicolumn{3}{c}{ Korsmeyer-Peppas } \\
\cline { 2 - 10 } & $\mathrm{K}_{0}\left(\mathbf{m g ~ h}^{-1}\right)$ & $\mathbf{R}^{2}$ & $\mathrm{~K}_{1}\left(\mathbf{h}^{-1}\right)$ & $\mathbf{R}^{2}$ & $\mathbf{K}_{\mathrm{H}}\left(\mathbf{h}^{-1 / 2}\right)$ & $\mathbf{R}^{2}$ & $\mathbf{n}$ & $\mathbf{K}_{\mathrm{kp}}\left(\mathbf{h}^{-1 / 3}\right)$ & $\mathbf{R}^{2}$ \\
F4 & 0.4504 & 0.9865 & -0.0076 & 0.7901 & 7.3939 & 0.9298 & 0.5190 & 0.7498 & 0.9296 \\
F7 & 0.2741 & 0.9541 & -0.0026 & 0.9816 & 5.3731 & 0.9918 & 0.5243 & 0.6531 & 0.9877 \\
F8 & 0.3627 & 0.9943 & -0.013 & 0.7859 & 5.1115 & 0.9713 & 0.2058 & 1.5378 & 0.9381 \\
F9 & 0.3157 & 0.9853 & -0.0033 & 0.9766 & 6.0465 & 0.9776 & 0.5705 & 0.5506 & 0.9496 \\
F11 & 0.2689 & 0.9822 & -0.0683 & 0.9876 & 5.2009 & 0.9938 & 0.5832 & 0.479 & 0.9944 \\
\hline
\end{tabular}

As shown in (Table 5), it was found that the examination of the correlation coefficient $\left(\mathrm{R}^{2}\right)$ for the selected formulations indicated that the drug release followed a diffusion-controlled mechanism from the in situ gelling liquid suppositories, as the values for Higuchi's square root of time (ranged from 0.9713 to 0.9938 ) were always higher in comparison to zero-order (ranged from 0.9541 to 0.9943 ) and first-order (ranged from 0.7859 to 0.9876 ). The release kinetics of the prepared in situ gelling liquid suppositories illuminated from the Korsmeyer-Peppas equation that the release exponent values (n) for (F4, F7, F9, and F11) were within the range of $0.5<n<1.0$ with the lowest value for $F 4$ and the highest value for F11. This observation indicated a non-Fickian (anomalous) release mechanism which occurs due to a combination of macromolecular chain relaxations and Fickian diffusion. Except for formulation F8 that has a release exponent value (n) $<0.5$ which was indicative of the Fickian drug release mechanism. Hence, it can be deduced from the results that F4 was selected as an optimum formula and the drug release was mainly following non-Fickian diffusion transport; this indicated that the drug release mechanism could be controlled by swelling of the polymer, followed by drug diffusion through the polymer and slow erosion of polymer $^{[68,69]}$.
FT-IR spectroscopy was carried out to establish the compatibility of metoclopramide $\mathrm{HCl}$ with polymers after the preparation of in situ gelling liquid suppositories. Individual FT-IR scanning of polymers [P188, P407, HPMC K15M] as shown in (fig. 4A, 4B and $4 \mathrm{C}$ ) respectively, the pure drug powder as shown in (fig. 4D); in addition to the in situ gelling liquid suppositories of comprising metoclopramide $\mathrm{HCl}(\mathrm{F} 4)$ as shown in (fig. 4E). Moreover, the FTIR of polymers with the drug and optimum formula F4 were all reconstructed and showed in (fig. 5).

The FT-IR spectrum for pure metoclopramide $\mathrm{HCl}$ was characterized by the principal absorption bands at $3454.62 \mathrm{~cm}^{-1}$ due to $\mathrm{O}-\mathrm{H}$ stretching mode of hydrate, $3377 \mathrm{~cm}^{-1}$ due to symmetric $\mathrm{NH}_{2}$ stretching vibration, $3311 \mathrm{~cm}^{-1}$ and $3198 \mathrm{~cm}^{-1}$ due to N-H stretching mode of amide, $2980.12 \mathrm{~cm}^{-1}$ and $2877.89 \mathrm{~cm}^{-1}$ due to $\mathrm{C}-\mathrm{H}$ stretching, $1631 \mathrm{~cm}^{-1}$ due to $\mathrm{C}=\mathrm{O}$ stretching of amide, $1597.11 \mathrm{~cm}^{-1}$ due to $\mathrm{NH}_{2}$ scissoring, $1539.25 \mathrm{~cm}^{-1}$ due to $\mathrm{N}-\mathrm{H}$ bending, $1265.35 \mathrm{~cm}^{-1}$ due to $\mathrm{C}-\mathrm{O}-\mathrm{C}$ vibration and 680.89 due to $\mathrm{C}-\mathrm{Cl}$ vibration ${ }^{[70,71]}$.

While FT-IR spectrum of P188 was distinguished by absorption peaks at $2885.6 \mathrm{~cm}^{-1}$ due to aliphatic stretching of C-H, $1344.43 \mathrm{~cm}^{-1}$ due to the in-plane bending of $\mathrm{O}-\mathrm{H}$, and $1109.11 \mathrm{~cm}^{-1}$ due to stretching 


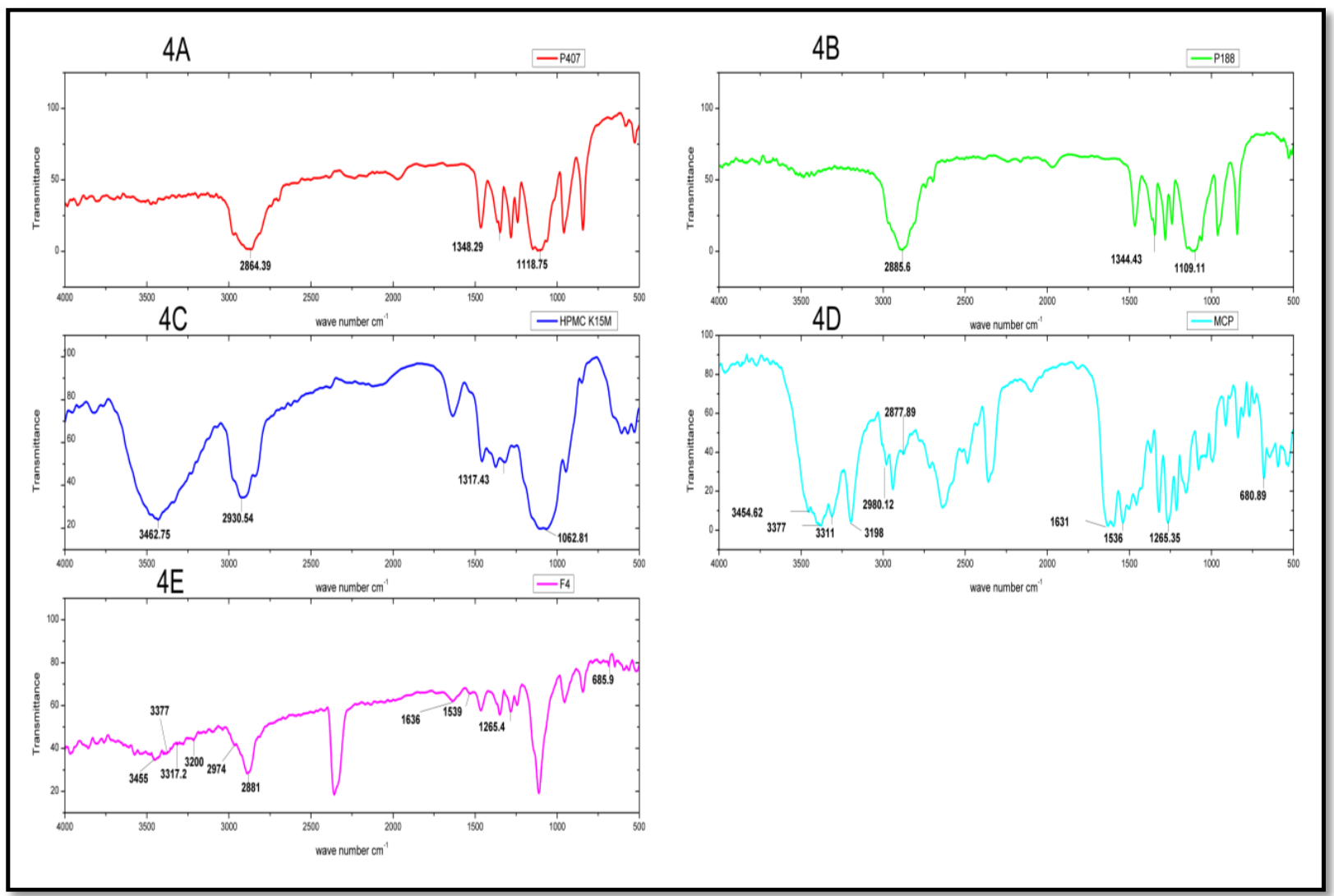

Fig. 4: The FT-IR spectrograms

FT-IR spectrograms represent 4A: P407, 4B: P188, 4C: HPMC K15M, 4D: metoclopramide HCl (MCP), and 4E: in situ gelling liquid suppository (F4).

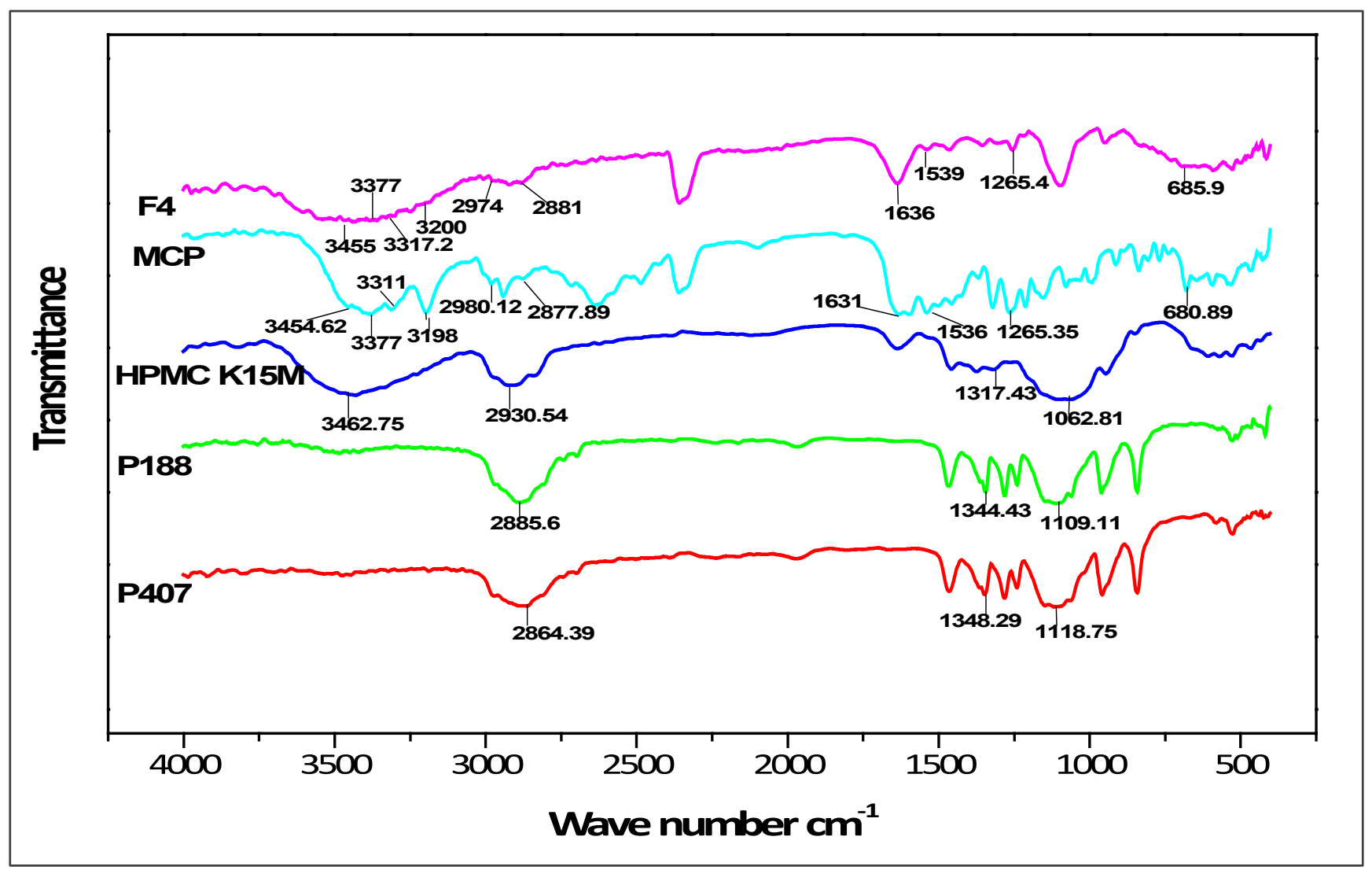

Fig. 5: The FT-IR spectrograms (reconstructed) 
of C-O. Moreover, the FT-IR spectrum of P407 was observed with the characteristic peaks at $2864.39 \mathrm{~cm}^{-1}$ due to aliphatic stretching of C-H, $1348.29 \mathrm{~cm}^{-1}$ due to in-plane bending of $\mathrm{O}-\mathrm{H}$, and $1118.75 \mathrm{~cm}^{-1}$ due to stretching of C-O. Besides, the FT-IR spectrum of HPMC K15M was represented by stretching of alkyl $\mathrm{C}-\mathrm{H}$ and phenolic $\mathrm{O}-\mathrm{H}$ at $2930.54 \mathrm{~cm}^{-1}$ and 3462.75 $\mathrm{cm}^{-1}$ respectively, the absorption peak at $1317.43 \mathrm{~cm}^{-1}$ that represented stretching of C-O- ether linkage. It also shows the stretching of the alcohol C-O group at $1062.81 \mathrm{~cm}^{-1[32,72]}$.

The FT-IR spectrum pattern for in situ gelling liquid suppository [F4] was compared with the FT-IR spectrum of the pure drug for endorsement of major functional groups. Altogether the characterized peaks of metoclopramide $\mathrm{HCl}$ with polymers have seemed and specified no significant difference in the peaks, suggesting that the drug and excipients were compatible. Furthermore, it shows that no interaction between metoclopramide $\mathrm{HCl}$ pure powder and the used polymers. Subsequently, it can be decided that the drug is chemically stable in the polymer matrix and can release with ease from in situ gelling liquid suppositories.

Put together, this study established a unique optimal formulation of metoclopramide $\mathrm{HCl}(\mathrm{F} 4)$ that led to the possibility of preparing successful in situ gelling liquid suppositories containing a combination of thermosensitive (P407 and P188) and mucoadhesive (HPM K15M) polymers. Where there was no drug precipitation with adequate viscosity and a proper syringeability time when it is anticipated to be applied to the rectum. Subsequently, this formulation possesses successful gelation temperature, $\mathrm{pH}$, and a satisfactory spreadability where a lack of irritation and leakage was recorded. On the other hand, this liquid suppository formulation gave significantly acceptable gel strength and a high mucoadhesion property that allows stagnation of the gel in the lower region of the rectum (in situ) to be as an advantage to protect the drug from the extended first-pass effect. As well, non-Fickian diffusion transport for drug dissolution profile was approved; suggesting that the drug release mechanism could be controlled by swelling of the polymer, followed by drug diffusion through the polymer and slow erosion which is the most challenging aspect of this drug delivery system. Consequently, these right and suitable in situ gelling liquid suppository candidates of metoclopramide $\mathrm{HCl}$ were established to be an effective, potential, and more convenient alternative than conventional oral dosage form for emetic patients.

\section{Acknowledgments:}

The authors would like to thank Mustansiriyah University (www. uomustansiriyah. edu. iq) BaghdadIraq for its support in the present work. Also, the authors would like to give great thanks and appreciation for assistant professor Dr. A. M. Rasheed in the department of pharmaceutical chemistry, college of pharmacy, Mustansiriyah University, Baghdad-Iraq, for his help and generosity. Deep regards to biorender.com for their facilitation to sketch some figures.

\section{REFERENCES}

1. Jannin V, Lemagnen G, Gueroult P, Larrouture D, Tuleu C. Rectal route in the 21 st century to treat children. Adv Drug Delivery Rev 2014;73:34-49.

2. Ham AS, Buckheit Jr RW. Designing and developing suppository formulations for anti-HIV drug delivery. Ther Deliv 2017;8:805-17.

3. Yong CS, Choi JS, Quan QZ, Rhee JD, Kim CK, Lim SJ, et al. Effect of sodium chloride on the gelation temperature, gel strength and bioadhesive force of poloxamer gels containing diclofenac sodium. Int J Pharm 2001;226:195-205.

4. Choi HG, Jung JH, Ryu JM, Yoon SJ, Oh YK, Kim CK. Development of in situ gelling and mucoadhesive acetaminophen liquid suppository. Int J Pharm 1998;165:3344.

5. Ryu JM, Chung SJ, Lee MH, Kim CK, Shim CK. Increased bioavailability of propranolol in rats by retaining thermally gelling liquid suppositories in the rectum. J Control Release 1999;59:163-72.

6. Jain S, Sandhu PS, Malvi R, Gupta B. Cellulose derivatives as thermoresponsive polymer: an overview. J Appl Pharm Sci 2013;3:139-44.

7. Ozsoy Y, Güngör S. Nasal route: an alternative approach for antiemetic drug delivery. Expert Opin Drug Deliv 2011;8:143953.

8. Jelvehgari M, Valizadeh H, Ziapour S, Rahmani M, Montazam $\mathrm{SH}$, Soltani S. Comparative study of different combinational mucoadhesive formulations of sumatriptan-metoclopramide. Adv Pharm Bull 2016;6:119-30.

9. Abdel-Rahman SI, Mahrous GM, El-Badry M. Preparation and comparative evaluation of sustained release metoclopramide hydrochloride matrix tablets. Saudi Pharm J 2009;17:283-8.

10. Mahajan HS, Gattani S. In situ gels of metoclopramide hydrochloride for intranasal delivery: in vitro evaluation and in vivo pharmacokinetic study in rabbits. Drug Deliv 2010;17:1927.

11. Yuan Y, Cui Y, Zhang L, Zhu HP, Guo YS, Zhong B, et al. Thermosensitive and mucoadhesive in situ gel based on poloxamer as new carrier for rectal administration of nimesulide. Int J Pharm 2012;430:114-9.

12. Pásztor E, Makó Á, Csóka G, Fenyvesi ZS, Benko R, Prosszer $\mathrm{M}$, et al. New formulation of in situ gelling metolose-based liquid suppository. Drug Develop Ind Pharm 2011;37:1-7.

13. El-Kamel A, El-Khatib M. Thermally reversible in situ gelling carbamazepine liquid suppository. Drug Deliv 2006;13:143-8. 
14. Kim JK, Kim MS, Park JS, Kim CK. Thermo-reversible flurbiprofen liquid suppository with HP- $\beta-C D$ as a solubility enhancer: improvement of rectal bioavailability. J Inclusion Phenom Macrocyclic Chem 2009;64:265-72.

15. Okur NU, Yoltaş A, Yozgatli V. Development and characterization of voriconazole loaded in situ gel formulations for ophthalmic application. Turkish J Pharm Sci 2016;13:3117.

16. Chaudhary G, Baby B, Rao BP, Rajarajan S, Sah J, Acharya U. Development and optimization of sustained release in situ gel for the treatment of ulcerative colitis. World J Pharm Pharm Sci 2017;6: 779-90.

17. Thomas LM, Khasraghi AH, Saihood AH. Preparation and evaluation of lornoxicam in situ gelling liquid suppository. Drug Invention Today. 2018;10:1556-63.

18. Ozguney I, Anita Kardhiqi A. Properties of bioadhesive ketoprofen liquid suppositories: preparation, determination of gelation temperature, viscosity studies and evaluation of mechanical properties using texture analyzer by $4 \mathrm{X} 4$ factorial design. Pharm Dev Technol 2014;19:968-75.

19. Lin HR, Tseng CC, Lin YJ, Ling MH. A novel in situ gelling liquid suppository for site-targeting delivery of anti-colorectal cancer drugs. J. Biomater Sci, Polym Ed 2012;23:807-22.

20. Barakat NS. In vitro and in vivo characteristics of a thermogelling rectal delivery system of etodolac. APPS Pharm Sci Tech 2009;10:724-31.

21. Tuğcu-Demiroz F. Development of in situ poloxamerchitosan hydrogels for vaginal drug delivery of benzydamine hydrochloride: Textural, mucoadhesive and in vitro release properties. Marmara Pharm J 2017;21:762-70.

22. Kunche HB, Ahmed MG, Rompicharla NC. Development and evaluation of in situ gels of moxifloxacin for the treatment of periodontitis. Ind J pharm 2012;23:141-6.

23. Schuetz YB, Gurny R, Jordan O. A novel thermoresponsive hydrogel based on chitosan. Eur J Pharm Biopharm 2008;68:19-25.

24. Ban E, Kim CK. Design and evaluation of ondansetron liquid suppository for the treatment of emesis. Arch Pharmacal Res 2013;36:586-92.

25. Özgüney I, Kardhiqi A, Yıldız G, Ertan G. In vitro-in vivo evaluation of in situ gelling and thermosensitive ketoprofen liquid suppositories. Eur J Drug Metab Pharmacokinet 2014;39:283-91.

26. Jaafar IS, Radhi AA. Formulation and in vitro evaluation of in situ liquid gelling suppository of promethazine $\mathrm{HCl}$. World $\mathrm{J}$ Pharm Res 2015;4:273-86.

27. Ramadan AA, Elbakry AM, Esmaeil AH, Khaleel SA. Pharmaceutical and pharmacokinetic evaluation of novel rectal mucoadhesive hydrogels containing tolmetin sodium. J Pharm Investig 2018;48:673-83.

28. Karthick RA, Devi DR, Hari BV. Investigation of sustained release mucoadhesive in situ gel system of secnidazole for the persistent treatment of vaginal infections. J Drug Deliv Sci Technol 2018;43:362-8.

29. Ramadass SK, Perumal S, Jabaris SL, Madhan B. Preparation and evaluation of mesalamine collagen in situ rectal gel: a novel therapeutic approach for treating ulcerative colitis. Eur J Pharm Sci 2013;48:104-10.

30. United States Pharmacopeia 41- NF 36, 2018; Baltimore, PP: 2699.

31. Al-Wiswasi NN, Al-Khedairy EB. Formulation and in vitro evaluation of in situ gelling liquid suppositories for naproxen. Iraqi J Pharm Sci 2008;17:31-8.
32. Garala K, Joshi P, Shah M, Ramkishan A, Patel J. Formulation and evaluation of periodontal in situ gel. Int J Pharm Invest 2013;3:29-41.

33. Qi H, Li L, Huang C, Li W, Wu C. Optimization and physicochemical characterization of thermosensitive poloxamer gel containing puerarin for ophthalmic use. Chem Pharm Bull 2006;54:1500-7.

34. Abd Elhady SS, Mortada ND, Awad GA, Zaki NM. Development of In Situ Gelling and Muco adhesive Mebeverine Hydrochloride solution for Rectal Administration. Saudi Pharmaceutical Journal. 2003;11:159-71.

35. Ryu JM, Chung SJ, Lee MH, Kim CK, Shim CK. Increased bioavailability of propranolol in rats by retaining thermally gelling liquid suppositories in the rectum. J Control Release 1999;59:163-72.

36. Deshkar SS, Patil AT, Poddar SS. Development of thermosensitive gel of fluconazole for vaginal candidiasis. Int J Pharm Pharm Sci 2016;8:391-8.

37. Zeng N, Dumortier G, Maury M, Mignet N, Boudy V. Influence of additives on a thermosensitive hydrogel for buccal delivery of salbutamol: relation Between micellization, gelation, mechanic and release Properties. Int J Pharm 2014;467:70-83.

38. Khan S, Gajbhiye C, Singhavi DJ, Yeole P. In situ gel of metoprolol tartrate: physicochemical characterization, in vitro diffusion and histological studies. Indian $\mathrm{J}$ Pharm Sci 2012;74:564-70.

39. Kaur R, Kumar S, Gupta GD. Preparation and evaluation of in situ gelling miconazole nitrate liquid vaginal suppository. Indo Am J Pharm Res 2017;7:1018-26.

40. Yong CS, Choi YK, Kim Y, Park BJ, Quan QZ, Rhee JD, et al. Physicochemical characterization and in vivo evaluation of thermosensitive diclofenac liquid suppository. Arch Pharmacal Res 2003;26:162-7.

41. Akl MA, Ismael HR, Abd Allah FI, Kassem AA, Samy AM. Tolmetin sodium-loaded thermosensitive mucoadhesive liquid suppositories for rectal delivery; strategy to overcome oral delivery drawbacks. Drug Develop Ind Pharm 2019;45:25264.

42. Al-Ani E, Martin C, Britland ST, Doudin K, Hill DJ. The effect of the source and the concentration of polymers on the release of chlorhexidine from mucoadhesive buccal tablets. Saudi Pharm J 2019;27:756-66.

43. Chen $\mathrm{MJ}$, Cheng $\mathrm{YM}$, Lai $\mathrm{PH}, \mathrm{Wu} \mathrm{JF}$, Hsu YC. In vitro biocompatibility of thermally gelling liquid mucoadhesive loaded curcuminoids in colorectal cancer chemoprevention. Int J Colorectal Dis 2012;27:869-78.

44. Ibrahim EA, Ismail S, Fetih G, Shaaban O, Hassanein $\mathrm{K}$, Abdellah NH. Development and characterization of thermosensitive pluronic-based metronidazole in situ gelling formulations for vaginal application. Acta Pharm 2012;62:5970 .

45. Narayana RC, Harish NM, Prabhakara P, Singh AK, Subrahmanyam EV. Formulation and in vitro evaluation of in situ gels containing secnidazole for vaginitis. Yakugaku Zasshi 2009;129:569-74.

46. Deepak YR, Ayyappan T, Shanmugam S, Sundaramoorthy $\mathrm{K}$, Vetrichelvan T. Development and in vitro evaluation of buccoadhesive metoclopramide hydrochloride tablet formulations. Int J Pharm Tech Res 2011;3:516-25.

47. Shinde JV, Mali KK, Dias RJ, Havaldar VD, Mahajan NS. In situ mucoadhesive nasal gels of metoclopramide hydrochloride: preformulation and formulation studies. J Pharm Res 2008;1:88-96. 
48. Liabot JM, Manzo RH. Double-layered mucoadhesive tablets containing nystatin. AAPS Pharm Sci Tech 2002;3:47-52.

49. Zaki NM, Awada GA, Mortada ND, Abd ElHady SS. Enhanced bioavailability of metoclopramide $\mathrm{HCl}$ by intranasal administration of a mucoadhesive in situ gel with modulated rheological and mucociliary transport properties. Eur J Pharm Sci 2007;32:296-307.

50. Vigani B, Faccendini A, Rossi S, Sandri G, Bonferoni MC, Grisoli $\mathrm{P}$, et al. Development of a mucoadhesive in situ gelling formulation for the delivery of Lactobacillus gasseri into vaginal cavity. Pharmaceutics 2019;11:511.

51. Karavana SY, Rençber S, Şenyiğit ZA, Baloğlu E. A new in situ gel formulation of itraconazole for vaginal administration. Pharmacol Pharm 2012;3:417-26.

52. Hadi MA, Mahtab T, Tabassum S, Mounika V, Unissa R. Development and In-vitro Evaluation of In-situ Nasal Gels of Zafirlukast. Der Pharmacia Lettre 2019;11:1-9.

53. Pose-Vilarnovo B, Rodríguez-Tenreiro C, Dos Santos JF, Vázquez-Doval J, Concheiro A, Alvarez-Lorenzo C, et al. Modulating drug release with cyclodextrins in hydroxypropyl methylcellulose gels and tablets. J Control Release 2004;94:351-63.

54. Majithiya RJ, Ghosh PK, Umrethia ML, Murthy RS. Thermoreversible-mucoadhesive gel for nasal delivery of sumatriptan. AAPS Pharm Sci Tech 2006;7:E80-6.

55. Ma J, Lin Y, Chen X, Zhao B, Zhang J. Flow behavior, thixotropy and dynamical viscoelasticity of sodium alginate aqueous solutions. Food Hydrocoll 2014;38:119-28.

56. Manna S, Lakshmia US, Racharla M, Sinha P, Kanthala LK, Kumar SP. Bioadhesive HPMC gel containing gelatin nanoparticles for intravaginal delivery of tenofovir. J App Pharm Sci 2016;6:22-29.

57. Firoz S, Padmini K, Padmasree K, Sravani N, Hemalatha A, Vennelarani Y. Formulation development and evaluation of carbopol-incorporated thermoreversible gels of pseudoephedrine for rectal drug delivery. Asian J Pharm Clin Res 2019;12:231-5.

58. Mittal N, Kaur G. In situ gelling ophthalmic drug delivery system: formulation and evaluation. J Appl Polym Sci 2014;131:1-9.

59. Paul A, Fathima KM, Nair SC. Intra nasal in situ gelling system of lamotrigine using ion activated mucoadhesive polymer. The Open Med Chem J 2017;11:222-244.

60. Rençber S, Karavana SY, Şenyiğit ZA, Eraç B, Limoncu $\mathrm{MH}$, Baloğlu E. Mucoadhesive in situ gel formulation for vaginal delivery of clotrimazole: formulation, preparation, and in vitro/in vivo evaluation. Pharm Dev Tech 2017;22:551-61.

61. Khodaverdi E, Ganji F, Tafaghodi M, Sadoogh M. Effects of formulation properties on sol-gel behavior of chitosan/ glycerolphosphate hydrogel. Iran Polym J 2013;22:785-90.

62. Venkatesh MP, Anis S, Kumar TMP. Design and development of an injectable in situ forming drug delivery system of methotrexate for the treatment of rheumatoid arthritis. J Drug Del Sci Tech 2013;23:445-53.

63. Desai V, Shah N. Formulation and Evaluation of Olmesartan medoxomil mouth dissolving film. J Pharm Sci Biosci Res 2014;4:201-6.

64. Akbari J, Enayatifard R, Saeedi M, Saghafi M. Influence of hydroxypropyl methylcellulose molecular weight grade on water uptake, erosion and drug release properties of diclofenac sodium matrix tablets. Trop J Pharm Res 2011;10:535-41.

65. Khatoon N, Rao NR, Reddy BM. Formulation and evaluation of oral fast dissolving films of montelukast sodium. Int J Pharm Sci Res 2014;5:1780-7.

66. Thomas LM. Formulation of floating in situ gel of metronidazole. Int J Pharm Pharm Sci 2014;6:265-9.

67. Wang LL, Zheng WS, Chen SH, Fang XQ. Development of in situ gelling and bioadhesive 5-Fluorouracil enema. Plos One 2013;8:e71037.

68. Reanmongkol W, Kaewnopparat N, Ratanajamit C. Development of tramadol hydrochloride rectal gel preparations and evaluation of analgesic activity in experimental animals. J Drug Deliv Sci Technol 2011;21:503-7.

69. Kassab HJ, Khalil YI. 5-Fluorouracil mucoadhesive liquid suppository formulation and evaluation. World J Pharm Res 2014;3:119-35.

70. Wang SL, Wong YC, Cheng WT, Lin SY. A continuous process for solid-state dehydration, amorphization and recrystallization of metoclopramide $\mathrm{HCl}$ monohydrate studied by simultaneous DSC-FTIR microspectroscopy. J Therm Anal Calorim 2011;104:261-4.

71. Narayanasamy R, Shabaraya R. Preparation and evaluation of a sustained release formulation of metoclopramide hydrochloride HPMC tablets. Marmara Pharm J 2017;3:71729.

72. Soni S, Ram V, Verma A. Formulation and investigation of crushed puffed rice-chitosan-HPMC based polymeric blends as carrier for sustained stomach specific drug delivery of piroxicam using 3(2) taguchi mathematical design studies. Int Current 